J. Lake Sci. (湖泊科学), 2012, 24(1): 67-74

http: //www. jlakes. org. E-mail : jlakes@niglas.ac.cn

(C) 2012 by Journal of Lake Sciences

\title{
基于生态适宜性分析的湖泊保护与利用一一湖北斧头湖为例
}

\author{
孔令阳 ${ }^{1}$, 李中强 ${ }^{1 * *}$, 王双玲 ${ }^{1}$, 杨兰芳 $^{1}$, 徐 军 $^{2}$ \\ $(1:$ 湖北大学资源环境学院, 武汉 430062) \\ (2: 中国科学院水生生物研究所,武汉 430062)
}

摘 要: 为了湖泊生态系统健康及湖泊资源的可持续利用, 需要根据湖泊的具体情况加强对湖泊生态系统的管理. 建立 在生态适宜性分析基础上的湖泊生态功能分区, 可为科学合理地开发湖泊资源、协调湖泊生态系统结构与功能提供依 据. 以湖北省斧头湖为对象, 在对斧头湖生态环境调查基础上,选取具有代表性的水质、生物及人为干扰因子; 根据《地表 水环境质量标准》(GB3838-2002) 确定水质评价等级,采用专家论证法确定生物及人为干扰因子评价等级,建立起湖泊 生态养殖适宜性评价等级体系; 采用主成分分析法确定评价因子权重, 并在 GIS 技术的支持下, 采用因子叠加法, 对斧头 湖生态养殖适宜性进行综合评价. 根据各区域生态养殖适宜性综合评价结果, 同时考虑到湖泊生态环境和综合资源保护 要求、斧头湖自然生态系统功能和生态渔业的可持续发展, 可将斧头湖划分为极适宜区、高度适宜区、中度适宜区、轻度 适宜区和较不适宜区; 各适宜区面积分别占斧头湖总面积的 $12.04 \% 、 24.81 \% 、 49.65 \% 、 9.58 \%$ 和 $3.92 \%$. 从湖泊生态 系统保护及渔业的可持续利用角度看, 极适宜区、高度适宜区适合开展生态养殖; 中度适宜区和轻度适宜区要以生态恢 复为主, 可进行一定规模的放养养殖; 较不适宜区应进行生态修复, 不适宜进行各种开发活动.

关键词: 生态适宜性; 湖泊;GIS; 保护与利用;斧头湖

\section{Lake conservation and utilization based on ecological suitability analysis: a case study of Lake Futou in Hubei Province}

KONG Lingyang ${ }^{1}$, LI Zhongqiang ${ }^{1}$, WANG Shuangling ${ }^{1}$, YANG Lanfang $^{1} \&$ XU Jun ${ }^{2}$

(1: Faculty of Resources and Environment, Hubei University, Wuhan 430062, P. R. China)

(2: Donghu Experimental Station of Lake Ecosystems, State Key Lab of Freshwater Ecology and Biotechnology, Institute of Hydrobiology, Chinese Academy of Sciences, Wuhan 430062, P. R. China)

\begin{abstract}
For the health of lake ecosystem and sustainable utilization of lake resources, it is necessary to manage the lake ecological suitability based on the lake-specific environmental conditions. Lake ecological suitability analysis can quantify the ecological function partitions, which can provide scientific foundation for rational utilization of lake resources and ecosystem management. Based on ecological investigation of the lake environment, ecological suitability in Lake Futou has been evaluated by selecting regional representative factors such as water quality, biological and man-made interference factors, utilizing GIS technology and using the model of multi-factor summation with different evaluation grade and weights. According to results of suitability evaluation for each region and the lake's ecological environment protection requirements, the spatial area of Lake Futou can be divided into extremely suitable region, highly suitable region, moderate suitable region, weak suitable region and non-suitable region. The area of each region is about $12.04 \%, 24.81 \%, 49.65 \%, 9.58 \%$ and 3.92\% of total area of Lake Futou, respectively. For the purpose of the protection and ecologically sustainable development of fisheries, the extremely and highly suitable regions are suitable for ecological aquaculture, and the moderate, wake and non-suitable regions must be restored to normal conditions from the present damaged ecosystem.
\end{abstract}

Keywords: Ecological suitability; lake; GIS; conservation and utilization; Lake Futou

* 国家自然科学基金项目(30870260)、湖北省杰出青年基金项目 (2010CDA098)、国家水体污染控制与治理科技重 大专项项目 (2008ZX07101-001) 和湖北省教育厅科学技术研究计划重点项目 (D20091009) 联合资助. $2011-01-$ 05 收稿;2011-04-01 收修改稿. 孔令阳,男,1984 年生, 硕士研究生; E-mail:konglingyang20504@ 163. com.

** 通信作者;E-mail:lizhq@ hubu. edu.cn. 
湖泊生态系统是由不同性质的生态要素构成的一个整体, 在由水体、生物、基质构成的生态格局中, 各 要素之间相互联系、相互作用 ${ }^{[1]}$, 人类对湖泊资源的开发活动不可避免地影响着湖泊生态环境 ${ }^{[2]}$. 目前, 我国大多数湖泊普遍存在生境退化、开发过度、生物多样性减少、水体富营养化等问题 ${ }^{[34]}$. 长江中下游地 区是我国重要的淡水湖泊分布区, 其中大多数为浅水湖泊, 该地区人口众多, 经济发展快, 生态环境复杂, 环境问题严重; 环境问题已经成为制约该区域经济发展的一个重要因素, 其中湖泊生态环境问题尤为 突出 ${ }^{[5]}$.

生态适宜性分析是根据区域自然资源与环境性能, 根据发展要求和资源利用要求, 划分资源与环境的 适宜性等级, 从而为制定区域生态发展战略, 引导区域空间的合理发展提供科学依据 ${ }^{[6]}$, 是协调复合生态系 统发展与环境保护关系的需要, 也是制订生态规划的基础 ${ }^{[7]}$. 通过生态适宜性分析, 有助于从生态系统的角 度全面认识社会、经济、环境之间的相互关系及其发展变化规律, 为科学合理地开发资源、协调系统结构与 功能提供依据 ${ }^{[8-9]}$. 自 20 世纪末以来, 国内外许多专家学者进行了各种生态系统的生态适宜性分析研究, 但 研究主要集中在城市建设、土地资源利用、森林开发保护、旅游资源开发等方面 ${ }^{[10-15]}$. 而且很多相关问题探 讨大多停留在描述性的分析阶段, 仅有的一些定量研究也主要集中在资源评价和环境承载力方面 ${ }^{[16]}$. 到目 前为止, 关于生态适宜性分析的湖泊利用与保护方面的研究极少, 仅见于对斧头湖生态敏感性分析的 研究 ${ }^{[17]}$.

斧头湖是长江中下游生态环境保护较好的大中型湖泊, 目前关于斧头湖的研究多集中在物种多样性、 群落结构及动态变化等方面 ${ }^{[18-20]}$. 本文以该湖的水生态环境调查资料为基础, 选取具有代表性的自然环境 因子和人为因子, 在 GIS 技术支持下, 采用因子叠加法对该湖泊进行生态养殖适宜性分析, 以期为斧头湖的 合理开发利用和资源可持续利用提供科学的参考依据.

\section{1 研究区域概况}

斧头湖 (29 $55^{\circ} \sim 30^{\circ} 07^{\prime} \mathrm{N}, 114^{\circ} 09^{\prime} \sim 114^{\circ} 20^{\prime} \mathrm{E}$ ) 位于湖北省东南部, 地跨咸宁 (咸安区) 、嘉鱼、江夏 3 市 县 (区), 是湖北省第四大湖; 其水域面积约 $130 \mathrm{~km}^{2}$, 湖岸线长 $430 \mathrm{~km}$, 平均水深 $2.9 \mathrm{~m}$, 蓄水量 $3.3 \times 10^{8} \mathrm{~m}^{3}$; 该湖共有 16 条人湖河流,通过金水河与长江相通. 是长江中下游一个典型的集渔业、调蓄、灌溉、航运等功 能于一体的功能型湖泊. 同时也是江汉湖群中水生植被保持较为完好的近郊湖泊之一, 是我国重要的水产 种质资源和物种 “基因库”, 其生物资源极为丰富, 是鱼类和野生生物的重要栖息地, 有较高的生物多样性、 遗传多样性和物种多样性, 具有巨大的生态价值和环境价值 ${ }^{[2,21]}$.

斧头湖流域土地利用现状以农业、水产养殖为主, 其水产养殖业规模大. 斧头湖的总体水质比较好, 湖 面上各围网内的水质相对稳定、均匀 ${ }^{[17]}$. 目前, 斧头湖所受的人为干扰主要表现在终年围网养殖、围网养殖 密度过大、机船频繁活动等. 由于无序过度开发以及斧头湖自身水位标准过低、水体交换困难、自然污染严 重等原因,导致水面大幅缩减、湿地面积逐步缩小、水位明显下降、水质开始恶化、水生生物资源遭到破坏. 大量的城市污水、工业废水以及含有农药、化肥的农田用水直接排人湖中, 少量养殖户大量投放饲料和添加 剂, 致使大量的有机物沉淀, 湖水不断富营养化, 加之有的养殖户为追求短期效益, 擅自引进外来种, 形成优 势群体,传统的水生生物物种和湿地环境受到威胁, 使水体本身的降解能力降低, 自净能力减弱 ${ }^{[20-21]}$.

\section{2 研究方法}

\section{1 评价因子的选取}

影响湖泊生态系统适宜性的因子有很多, 但在不同区域影响生态系统适宜性的因子各异. 因子的选取 既要反映评价单元地域差异的本底特征, 又要具有相对独特性和不可替代性. 本研究根据斧头湖的湖泊 生态养殖功能和合理利用需要, 在分析斧头湖现状特征基础上, 遵循评价因子的可计量、主导性、代表 性和可操作性原则 ${ }^{[9]}$, 选取影响斧头湖资源可持续利用和生态渔业可持续发展的 9 个主要因子, 从性 质和特点上分为非生物因子和生物因子. 其中非生物因子包括高锰酸盐指数 $\left(\mathrm{COD}_{\mathrm{Mn}}\right)$ 、总氮 $(\mathrm{TN})$ 、总 磷 $(\mathrm{TP}) 、 \mathrm{pH}$ 、浊度 ( Turb) 、溶解氧 ( DO), 生物因子包括植被盖度、植物种数以及人为干扰因子距航道 距离. 


\section{2 数据采集与处理}

各评价因子数据为 2009 年 4 月和 9 月两次在斧头湖 现场采集而得,共选择 29 个采样点(图 1). $\mathrm{pH}$ 值、溶解氧 和浊度用多功能水质监测仪 (Hydoro lab) 在现场测得; 高 锰酸盐指数分析采用高锰酸盐法 (GB11892-1989) ; 总磷 测定采用钿酸铵分光光度法; 植被盖度指所调查区域植被 在水面的覆盖率;植物种类是指群落中所有水生植物种类 数量; 航道因子主要考虑水面航行对湖泊生态环境的影 响, 以距航道远近为标准进行取值, 数据取自斧头湖围栏 养殖空间布局图. 在 ARCGIS 9.3 软件支持下, 获取评价指 标的属性数据, 并建立相应的空间数据库, 通过对评价因 子的空间叠加, 获取评价单元的分值, 根据各评价单元的 分值, 对不同目标下湖泊利用的适宜程度进行判定 划分 ${ }^{[21-24]}$.

\section{3 生态适宜性等级划分}

为了较好地反映斧头湖生态环境质量及生态适宜

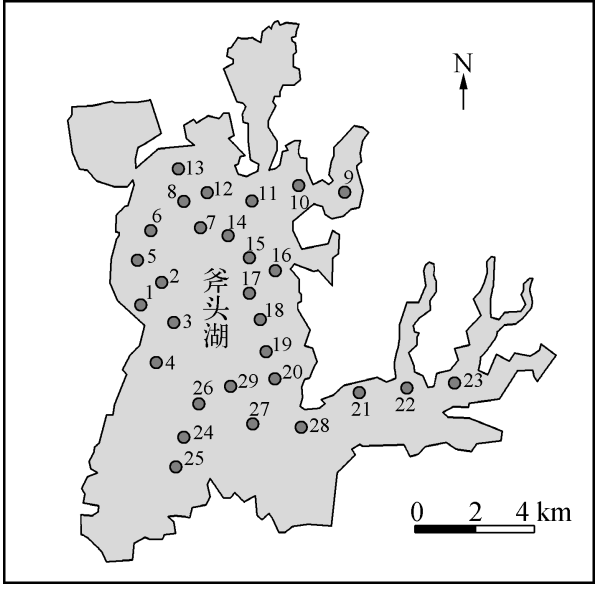

图 1 斧头湖生态环境因子采样点分布

Fig. 1 Sampling sites of eco-environment factors in Lake Futou 度, 根据各因子中不同要素对生态适宜度重要性程度的 不同, 对各个因子分别赋予不同的等级值,适宜性等级按极适宜、高度适宜、中度适宜、低度适宜、较不 适宜分别取值 $9 、 7 、 5 、 3 、 1$. 某一区域较高的等级值表示该因子具有较高的生态适宜性, 各适宜性分 级见表 1 .

表 1 斧头湖各位点适宜性分级

Tab. 1 Suitability grading of each sampling site in Lake Futou

\begin{tabular}{|c|c|c|c|c|c|c|}
\hline \multirow{2}{*}{ 综合指标 } & \multirow{2}{*}{ 评价因子 } & \multicolumn{5}{|c|}{ 评价等级 } \\
\hline & & 极适宜 & 高度适宜 & 中度适宜 & 低度适宜 & 较不适宜 \\
\hline \multirow[t]{6}{*}{ 水质 } & $\mathrm{DO} /(\mathrm{mg} / \mathrm{L})$ & $\geqslant 7.5$ & $7.5 \sim 6.0$ & $6.0 \sim 5.0$ & $5.0 \sim 3.0$ & $3.0 \sim 2.0$ \\
\hline & $\mathrm{COD}_{\mathrm{Mn}} /(\mathrm{mg} / \mathrm{L})$ & $0 \sim 2.0$ & $2.0 \sim 4.0$ & $4.0 \sim 15$ & $15 \sim 20$ & $20 \sim 30$ \\
\hline & $\mathrm{TN} /(\mathrm{mg} / \mathrm{L})$ & $\leqslant 0.2$ & $0.2 \sim 0.5$ & $0.5 \sim 1.0$ & $1.0 \sim 1.5$ & $1.5 \sim 2.0$ \\
\hline & $\mathrm{TP} /(\mathrm{mg} / \mathrm{L})$ & $\leqslant 0.01$ & $0.01 \sim 0.025$ & $0.025 \sim 0.05$ & $0.05 \sim 0.10$ & $0.10 \sim 0.20$ \\
\hline & $\mathrm{pH}$ & $6.8 \sim 7.2$ & $\begin{array}{c}6.2 \sim 6.8, \\
7.2 \sim 7.8\end{array}$ & $\begin{array}{c}5.6 \sim 6.2, \\
7.8 \sim 8.4\end{array}$ & $\begin{array}{c}5.0 \sim 5.6 \\
8.4 \sim 9.0\end{array}$ & $\begin{array}{c}4.4 \sim 5.0 \\
9.0 \sim 9.6\end{array}$ \\
\hline & 浊度 & $0 \sim 7$ & $7 \sim 14$ & $14 \sim 21$ & $21 \sim 28$ & $28 \sim 35$ \\
\hline \multirow[t]{2}{*}{ 植被 } & 植被盖度/\% & $\geqslant 50$ & $50 \sim 40$ & $40 \sim 30$ & $30 \sim 20$ & $\leqslant 20$ \\
\hline & 植物种类(物种) & $\geqslant 5$ & $4 \sim 5$ & $3 \sim 4$ & $2 \sim 3$ & $1 \sim 2$ \\
\hline 人为干扰 & 距航道距离/km & $>1$ & $1 \sim 0.7$ & $0.7 \sim 0.4$ & $0.4 \sim 0.1$ & $\leqslant 0.1$ \\
\hline
\end{tabular}

\section{4 评价因子的权重评定}

本文采取主成分分析方法来确定各适宜因子的权重值 ${ }^{[25]}$, 把 $\mathrm{COD}_{\mathrm{Mn}} 、 \mathrm{DO} 、 \mathrm{TN} 、 \mathrm{TP} 、 \mathrm{pH}$ 、浊度、植被盖 度、植物种类、距航道距离作为指标, 把 29 个采样点作为样本构成评价斧头湖生态适宜性的评价指标体系. 在计算机上对原始数据进行标准差标准化处理,选取特征值大于 1 的成分. 利用 SPSS 17.0 软件对 29 个样 本的数据进行分析, 根据累积贡献率的大小, 从特征根和特征向量中选取几个较大特征根及其对应特征向 量, 依据人选的特征根及其特征向量值大小进行权重赋值.

\section{5 生态适宜性综合评价方法}

本文采用指数加权求和法进行综合评价. 生态适宜性评价模型采用指标得分的加权求和方式得到, 计 算公式为: $S_{i}=\sum X_{i} \cdot P_{i}$, 式中, $S_{i}$ 为适宜度总得分; $X_{i}$ 为第 $i$ 个指标总得分; $P_{i}$ 为第 $i$ 个指标的权重; $i$ 分别取 
值 $1 \sim 9$.

根据各位点所得综合值, 在 Arcgis 9.3 空间分析中, 利用采样点数据对研究区内的其他未知区域的特征 数据进行推理和估计, 建立水质、植被和人为干扰影响因子适宜性点状矢量分布图, 最后采用 GIS 矢量叠加 技术得到生态适宜性综合评价图.

\section{3 结果}

\section{1 各适宜因子权重赋值的确定}

从主成分的线性表示 (表 2 ) 来看, 构成 $F_{1}$ 中植物种类、植被盖度因子的系数最大, 对 $F_{1}$ 的变化起主导作 用, 其方程为: $F_{1}=0.46 \times Z_{\mathrm{DO}}-0.01 \times Z_{\mathrm{COD}_{\mathrm{w}}}-0.22 \times Z_{\mathrm{TN}}-0.36 \times Z_{\mathrm{TP}}+0.17 \times Z_{\mathrm{pH}}-0.25 \times Z_{\text {浊度 }}+0.48 \times$

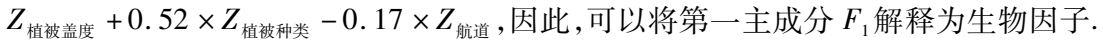

表 2 相关系数矩阵特征值及贡献率

Tab. 2 Eigenvalues and contribution of correlation matrix

\begin{tabular}{|c|c|c|c|c|c|c|}
\hline \multirow{2}{*}{ 成分 } & \multicolumn{3}{|c|}{ 初始特征值 } & \multicolumn{3}{|c|}{ 提取平方和载人 } \\
\hline & 合计 & 方差百分比 & 累积百分比 & 合计 & 方差百分比 & 累积百分比 \\
\hline 1 & 2.666 & 29.628 & 29.628 & 2.666 & 29.628 & 29.628 \\
\hline 2 & 1.630 & 18.110 & 47.737 & 1.630 & 18.110 & 47.737 \\
\hline 3 & 1.329 & 14.765 & 62.502 & 1.329 & 14.765 & 62.502 \\
\hline 4 & 0.943 & 10.473 & 72.975 & & & \\
\hline 5 & 0.739 & 8.213 & 81.188 & & & \\
\hline 6 & 0.675 & 7.496 & 88.684 & & & \\
\hline 7 & 0.452 & 5.021 & 93.705 & & & \\
\hline 8 & 0.379 & 4. 208 & 97.913 & & & \\
\hline 9 & 0.188 & 2.087 & 100.000 & & & \\
\hline
\end{tabular}

构成 $F_{2}$ 中 $\mathrm{COD}_{\mathrm{Mn}}$ 和浊度因子的系数最大, 对 $F_{2}$ 的变化起主导作用, 其方程为: $F_{2}=0.25 \times Z_{\mathrm{DO}}+0.65 \times$ $Z_{\mathrm{COD}_{\mathrm{Nu}}}+0.06 \times Z_{\mathrm{TN}}+0.38 \times Z_{\mathrm{TP}}-0.14 \times Z_{\mathrm{pH}}+0.47 \times Z_{\text {沙度 }}+0.32 \times Z_{\text {植被盖度 }}+0.10 \times Z_{\text {植被种类 }}+0.14 \times Z_{\text {航道, }}$, 因 此, 可以将第二主成分 $F_{2}$ 解释为水质因子.

构成 $F_{3}$ 中 $\mathrm{TN}$ 和航道的系数最大, 对 $F_{3}$ 的变化起主导作用, 其方程为: $F_{3}=0.10 \times Z_{\mathrm{DO}}+0.01 \times Z_{\mathrm{COD}_{\mathrm{Nu}}}+$ $0.53 \times Z_{\mathrm{TN}}-0.34 \times Z_{\mathrm{TP}}-0.49 \times Z_{\mathrm{pH}}-0.25 \times Z_{\text {浊度 }}+0.17 \times Z_{\text {植被盖度 }}-0.05 \times Z_{\text {植被种类 }}+0.50 \times Z_{\text {航道, 因此, 可以 }}$ 将第三主成分 $F_{3}$ 解释为水质及人为干扰因子 (表 3 ).

表 3 特征值对应的特征向量

Tab. 3 Eigenvectors of the corresponding characteristic

\begin{tabular}{ccrcrrrrrr}
\hline 主成分 & $\mathrm{DO}$ & $\mathrm{COD}_{\mathrm{Mn}}$ & $\mathrm{TN}$ & $\mathrm{TP}$ & $\mathrm{pH}$ & 浊度 & 植被盖度 & 植物种类 & 航道 \\
\hline 1 & 0.46 & -0.01 & -0.22 & -0.36 & 0.17 & -0.25 & 0.48 & 0.52 & -0.17 \\
2 & 0.25 & 0.65 & 0.06 & 0.38 & -0.14 & 0.47 & 0.32 & 0.10 & 0.14 \\
3 & 0.10 & 0.01 & 0.53 & -0.34 & -0.49 & -0.25 & 0.17 & -0.05 & 0.50 \\
\hline
\end{tabular}

主成分的方差贡献率和主成分 $\left(F_{1} \sim F_{3}\right)$ 与原性状 $\left(Z_{\mathrm{D} 0} \sim Z_{\text {艏 }}\right)$ 的相关矩阵的特征向量表明: 影响斧头 湖生态适宜性的主要因子为生物因子, 其次是水质和人为干扰因子, 其他指标 $\mathrm{pH}$ 、 TP、浊度和 $\mathrm{DO}$ 等为次要 评价因子. 根据各选择因子对各主成分影响的大小、选择因子对湖泊生态功能的影响程度以及该因子受环 境因素影响的可变性, 分别赋予不同权重 (表 3 ). 权重赋值如下: 水质因子权重总值为 0.61 , 其中 DO:0.04; $\mathrm{COD}_{\mathrm{Mn}}: 0.18 ; \mathrm{TN}: 0.15 ; \mathrm{TP}: 0.10 ; \mathrm{pH}: 0.04$; 浊度: 0.10 ; 植被因子权重总值为 0.29 , 其中植被盖度: 0.14 ; 植物 
种类: 0.15 ; 人为干扰因子航道权重值为 0.10 . 根据各因子调查数据及权重值, 计算得出斧头湖各样点生态 适宜性分析评价结果 (表 4 ).

表 4 斧头湖各位点生态适宜性分析评价结果

Tab. 4 Results of eco-environmental suitability analysis of sampling sites in Lake Futou

\begin{tabular}{|c|c|c|c|c|c|c|c|c|c|c|}
\hline 样点 & DO & $\mathrm{pH}$ & $\mathrm{TN}$ & $\mathrm{TP}$ & $\mathrm{COD}_{\mathrm{Mn}}$ & 浊度 & 植被盖度 & 植物种类 & 航道 & 综合评价值 \\
\hline 1 & 0.28 & 0.30 & 1.05 & 0.70 & 1.62 & 0.9 & 0.98 & 0.45 & 0.7 & 6.98 \\
\hline 2 & 0.68 & 0.50 & 1.05 & 0.90 & 1.62 & 0.9 & 0.70 & 0.30 & 0.3 & 6.95 \\
\hline 3 & 0.12 & 0.50 & 1.05 & 0.90 & 1.62 & 0.7 & 0.98 & 0.30 & 0.5 & 6.67 \\
\hline 4 & 0.04 & 0.50 & 1.05 & 0.50 & 1.62 & 0.3 & 0.70 & 0.15 & 0.5 & 5.36 \\
\hline 5 & 0.36 & 0.30 & 1.05 & 0.50 & 1.62 & 0.7 & 0.70 & 0.45 & 0.7 & 6.38 \\
\hline 6 & 0.36 & 0.50 & 1.05 & 0.90 & 1.62 & 0.7 & 0.70 & 0.30 & 0.7 & 6.83 \\
\hline 7 & 0.36 & 0.50 & 1.05 & 0.50 & 1.62 & 0.7 & 0.70 & 0.45 & 0.3 & 6.18 \\
\hline 8 & 0.28 & 0.30 & 1.05 & 0.50 & 1.26 & 0.5 & 0.70 & 0.45 & 0.7 & 5.74 \\
\hline 9 & 0.36 & 0.10 & 1.35 & 0.50 & 1.26 & 0.7 & 0.98 & 0.60 & 0.1 & 5.95 \\
\hline 10 & 0.36 & 0.50 & 1.35 & 0.90 & 1.26 & 0.5 & 0.98 & 0.60 & 0.5 & 6.95 \\
\hline 11 & 0.36 & 0.30 & 1.05 & 0.50 & 1.26 & 0.5 & 0.98 & 0.30 & 0.9 & 6.15 \\
\hline 12 & 0.36 & 0.50 & 1.05 & 0.70 & 1.26 & 0.7 & 0.70 & 0.45 & 0.3 & 6.02 \\
\hline 13 & 0.28 & 0.10 & 1.35 & 0.90 & 1.26 & 0.7 & 0.98 & 0.45 & 0.9 & 6.92 \\
\hline 14 & 0.28 & 0.50 & 1.35 & 0.90 & 1.26 & 0.5 & 0.70 & 0.45 & 0.5 & 6.44 \\
\hline 15 & 0.36 & 0.50 & 1.35 & 0.90 & 1.26 & 0.7 & 0.70 & 0.60 & 0.5 & 6.87 \\
\hline 16 & 0.36 & 0.50 & 1.35 & 0.70 & 1.62 & 0.7 & 0.98 & 0.45 & 0.3 & 6.96 \\
\hline 17 & 0.28 & 0.30 & 1.35 & 0.90 & 1.62 & 0.7 & 0.42 & 0.45 & 0.3 & 6.32 \\
\hline 18 & 0.36 & 0.30 & 1.35 & 0.90 & 0.90 & 0.7 & 0.70 & 0.30 & 0.5 & 6.01 \\
\hline 19 & 0.36 & 0.30 & 1.35 & 0.90 & 1.62 & 0.7 & 0.70 & 0.30 & 0.5 & 6.73 \\
\hline 20 & 0.36 & 0.50 & 1.35 & 0.90 & 1.62 & 0.7 & 0.42 & 0.30 & 0.3 & 6.45 \\
\hline 21 & 0.36 & 0.50 & 1.35 & 0.90 & 1.62 & 0.9 & 0.70 & 0.60 & 0.5 & 7.43 \\
\hline 22 & 0.36 & 0.50 & 1.35 & 0.90 & 1.62 & 0.7 & 1.26 & 0.60 & 0.5 & 7.79 \\
\hline 23 & 0.20 & 0.50 & 1.35 & 0.90 & 1.62 & 0.7 & 1.26 & 0.60 & 0.5 & 7.63 \\
\hline 24 & 0.20 & 0.10 & 1.05 & 0.30 & 1.62 & 0.7 & 0.42 & 0.30 & 0.1 & 4.79 \\
\hline 25 & 0.36 & 0.50 & 1.35 & 0.10 & 1.26 & 0.1 & 0.28 & 0.30 & 0.1 & 4.35 \\
\hline 26 & 0.28 & 0.10 & 1.35 & 0.50 & 1.62 & 0.7 & 0.28 & 0.30 & 0.3 & 5.43 \\
\hline 27 & 0.20 & 0.50 & 1.35 & 0.50 & 1.26 & 0.7 & 0.28 & 0.30 & 0.7 & 5.79 \\
\hline 28 & 0.20 & 0.30 & 1.35 & 0.50 & 1.62 & 0.7 & 0.28 & 0.45 & 0.7 & 6.10 \\
\hline 29 & 0.20 & 0.50 & 1.05 & 0.10 & 1.26 & 0.7 & 0.42 & 0.15 & 0.1 & 4.48 \\
\hline
\end{tabular}

\section{2 斧头湖生态适宜性综合评价及分区}

根据各区域适宜性因子分值, 同时考虑到湖泊生态环境和综合资源保护要求, 湖泊主要功能间的统筹 与协调, 湖泊生态功能的建设与修复, 湖泊水域生态效益、经济效益、社会效益的协调与提升, 为了斧头湖区 的自然生态系统与周边地区的社会经济系统协调统一和整个湖区生态系统走向良性循环 ${ }^{[26]}$. 将斧头湖综合 生态适宜类别适应区划分为五类: 极适宜区、高度适宜区、中度适宜区、轻度适宜区和较不适宜区. 极适宜区 的适宜性综合评价值在 7.2 8.0 之间,高度适宜区的适宜性综合评价值在 6.4 7.2 之间, 中度适宜区的适 宜性综合评价值在5.6 6.4 之间, 轻度适宜区综合评价值在 4.8 5.6 之间, 较不适宜区的适宜性综合评价 


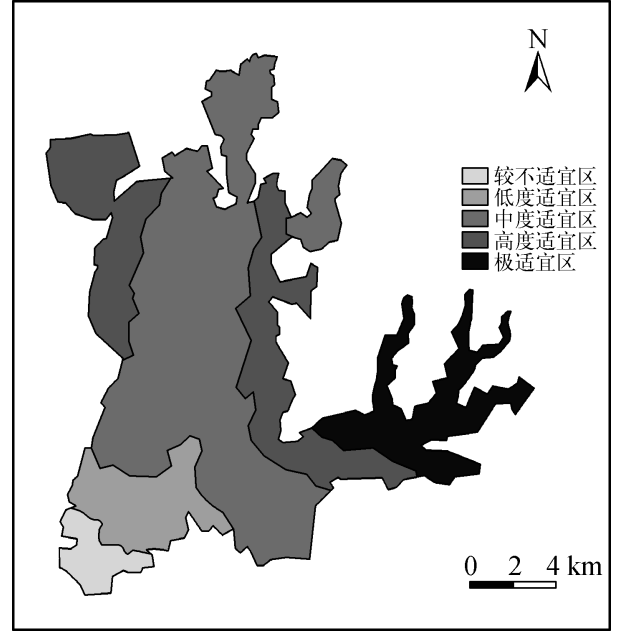

图 2 斧头湖生态适宜性分区

Fig. 2 Spatial features of the ecological suitability analysis in Lake Futou
值在 $4.0 \sim 4.8$ 之间 (图 2 和表 5).

3.2 .1 极适宜区 主要分布在斧头湖东南部, 占整个湖泊 水域面积的 $12.04 \%$. 该区域水位浅, 水质好, 植被覆盖率 也高, 物种丰富, 生态系统稳定, 对人类干扰活动的抵抗力 强, 且生态系统受损后恢复能力强. 该区域适合发展水产 生态养殖, 发展高档次原生态水产品, 同时可作为重要物 种栖息区, 开展科学研究工作. 需禁止围网养殖和水草收 割, 严格控制人湖污染物排放, 以保证生态系统的稳定和 资源的可持续利用.

3.2 .2 高度适宜区 主要分布在斧头湖东岸以及西北部 部分地区, 占整个湖泊水域面积的 $24.81 \%$. 该区域水质 好, 植被覆盖率高, 物种丰富, 生态重要性指数高; 受生态 环境约束较低, 对人类活动干扰的抵抗力强, 且受损后恢 复能力强. 该区可依据当地的自然条件、现状基础和发展 潜力来发展水产生态养殖, 优选养殖品种、提高水产品档 次、打造斧头湖水产品知名品牌. 同时必须控制开发强度, 控制围网和网箱密度, 对围网养殖采取轮养轮休, 减少投 饵量, 恢复沉水植物, 促进该区域生态系统的良性发展.

表 5 斧头湖生态适宜性分析结果

Tab. 5 Results of the ecological suitability analysis in Lake Futou

\begin{tabular}{ccccc}
\hline 生态适宜性类别 & 适宜性指数 & 面积 $/ \mathrm{hm}^{2}$ & 比例 $/ \%$ & 适用方向 \\
\hline 极适宜区 & $7.2 \sim 8.0$ & 1541.12 & 12.04 & 生态养殖、物种保护 \\
高度适宜区 & $6.4 \sim 7.2$ & 3175.68 & 24.81 & 生态养殖、物种保护 \\
中度适宜区 & $5.6 \sim 6.4$ & 6355.20 & 49.65 & 控制养殖、保护恢复 \\
轻度适宜区 & $4.8 \sim 5.6$ & 1226.24 & 9.58 & 控制养殖、保护恢复 \\
较不适宜区 & $4.0 \sim 4.8$ & 501.76 & 3.92 & 生态恢复 \\
\hline
\end{tabular}

3.2 .3 中度适宜区 主要分布在斧头湖中部大部分水域, 占整个湖泊水域面积的 $49.65 \%$. 该区域水位较 深, 水质比较好, 挺水植物、沉水植物分布较广泛, 植被覆盖率较高, 物种比较丰富; 生态系统较为稳定, 受干 扰后恢复能力较强. 本区不宜进行大规模围网养殖, 可发展一定规模的放养, 需注意鱼类和水产品的品种组 合和数量配套, 控制经济产出规模和发展效率, 同时要进行植被恢复和休渔, 以保证生态系统的良性发展和 生物资源的可持续利用.

3.2 .4 轻度适宜区 主要分布在斧头湖西南部, 占整个湖泊水域面积的 $9.58 \%$. 该区域水质较差, 植被覆盖 度较低, 且由于围网养殖、航运和过度收割水草, 致使水草减少, 属生态系统较为脆弱区. 较易遭受人为干 扰, 对人类干扰活动反应程度强烈, 人为干扰导致生态失衡的可能性大, 生态系统受损后较难恢复. 本区不 适宜进行水产养殖, 但可发展种植, 如莲 (Nelumbo nucifera) 、苂实(Euryale ferox) 和菱 (Trapa bispinosa) 等, 既 有助于恢复植被净化水质又能获得一定的经济效益. 本区需要严禁收割水草, 减少人为破坏, 严格控制外源 性污染的输人, 以逐步恢复水质,恢复生态环境.

3.2 .5 较不适宜区 该区域分布在斧头湖的最西南部, 占整个湖泊水域面积的 $3.92 \%$, 比例较小. 该区域位 于斧头湖最大的人湖河流——洤河的人湖口, 涂河携带大量的污染物人湖,附近居民生活污水部分排人湖 中, 导致该区域水体中氮、磷含量超标, 水质差, 植被少; 生态系统不稳定, 对人类活动干扰的反应程度强烈, 受到人为干扰后的抵抗力和恢复力均很弱, 人为干扰导致生态失衡的可能性极大. 该区域可作为纳污区, 截 流沉积物、消化分解废弃物等, 需加强人湖河流水质监控, 严格禁止向湖内超标排放污水, 以有效控制水质; 
重建和恢复水生植被, 增加水生植被密度, 以增强水生植被降解污染物的能力, 净化斧头湖湖区水质, 逐步 恢复生态环境.

\section{4 讨论}

湖泊生态适宜性分析和生态敏感性分析是从两个不同方面对湖泊生态环境进行的分析. 相对生态敏感 性分析而言, 生态适宜性分析是从另一个侧面来分析生态系统的稳定性, 是从肯定的角度来实现对生态系 统的利用和保护; 在对斧头湖敏感性分析研究中, 各级评价因子权重的确定采用的是专家打分法,易受主观 认识影响. 相对于对斧头胡生态敏感性分析而言,本研究采用的评价方法可能更加科学、合理; 在适宜性因 子选取方面, 考虑到水生植物和人类活动的影响,增加了植物种类和人为干扰因子; 在权重赋值方面采用主 成分分析方法确定权重值,降低了赋值的主观性. 本研究中生态适宜性低的区域与斧头湖生态敏感性分析 中的生态敏感性高的地区对应,生态适宜性高的区域与生态敏感性低的区域相对应. 综合比较本文与斧头 湖生态敏感性分析的研究结果, 发现两文评价结果具有一致性 ${ }^{[17]}$,在一定程度上说明了专家打分法具有一 定的科学性.

同时,我们研究发现本文在对评价因子的选取上有一定的局限性,指标体系由于数据获取方面的原因, 造成了指标选取较少, 如人为干扰因子有很多, 本文只选取了距航道距离这一个因子. 在以后的研究中需要 注意以下几个问题 ${ }^{[27]}$ : 采用更多的因子,如生物量因子、底栖生物因子、基质因子以及湖滨带植被因子、沿岸 土地利用因子等; 选取合适的时空尺度,各因子生命周期及生态位的差异, 分别反映河流湖泊生态系统不同 空间和时间尺度上健康状况的变化; 在用不同生物类群指标进行评价时,需要考虑取样尺度及频度; 选取参 照点条件, 建立湖泊湿地快速评价指标体系, 结合参照点条件,进行生态系统的综合性评价.

\section{5 参考文献}

[1 ] 金相灿, 王圣瑞, 姜 霞. 湖泊水一沉积物界面三相结构模式的初步研究. 环境科学研究, 2004, 17 (增刊) : 1-10.

[2] 谢 平, 崔奕波. 长江中下游湖泊生物多样性与渔业发展. 水生生物学报, 1996, 20(增刊) : 1-5.

[ 3 ] 金相灿. 湖泊富营养化调查规范: 第二版. 北京: 中国环境科学出版社, 1990: 7-10.

[4] 蔡述明, 杜 䎣. 江汉湖群湖泊资源特点及其开发利用保护. 华中师范大学学报: 自然科学版, 2000, 34 (4): $476-481$

[ 5 ] 邓宏兵. 江汉湖群演化与湖区可持续发展研究. 北京: 经济科学出版社, 2005: 82-91,125-129.

[ 6 ] 欧阳志云, 王如松, 符贵南. 生态位适宜度模型及其在土地利用适宜性评价中的应用. 生态学报, 1996, 16 (2) : 113-120.

[7] 李 川. 生态适宜度评价在工业园区规划环评中的应用. 环境科学与管理, 2009, 34(8): 180-183.

[ 8 ] 刘 康, 李团胜. 生态规划一一理论、方法、应用. 北京: 化学工业出版社, 2004: 40-49,55-62.

[ 9 ] 焦 胜, 曾光明, 曹麻茹. 城市生态规划概论. 北京: 化学工业出版社, 2006: 74-183.

[10] 陈昌勇, 尹海伟, 徐建刚. 吴江东部地区城镇发展用地生态适宜性评价. 陕西师范大学学报: 自然科学版, 2005, 33(3) : 114-120.

[11］白 琳，王 秀. 抚顺市生态适宜性分区研究. 环境保护与循环经济, 2009, 29(8) : 70-74.

[12］关小克, 张风荣, 郭力娜等. 北京市耕地多目标适宜性评价及空间布局研究. 资源科学, 2010, 32(3): 580-587.

[13］李 灿, 罗海波, 刘 方等. 磷矿废弃土地生态适宜性评价初探. 广东土地科学, 2010, 9(1) : 24-26.

[14] 问志平, 李 昕, 张俊杰. 郑州森林生态城林地适宜性评价. 河南农业大学学报, 2006, 40 (3) : 246-249.

１5］梁红玲, 李忠武, 叶芳毅等. 长沙市旅游开发生态适宜性评价. 城市环境与城市生态, 2009, 22 (6) : 31-34.

[16] 张振国, 贾铁飞. 基于 DEM 和 RS 的旅游开发生态环境适宜性评价研究. 干旱区资源与环境, 2007, 21 (6) : 63-67.

[17］李中强, 王双玲, 杨 梅等. 基于生态敏感性分析的湖泊保护与利用. 长江流域资源与环境, $2010,19(6)$ ： 714-718.

[18］龚珞军, 张仕萍, 熊邦喜等. 不同类型湖泊夏季浮游生物多元聚类分析. 水生生物学报, 2010,34: 43-50.

[19] 胡军华, 张春兰, 胡慧建. 长江中游湖泊鱼类物种多样性结构及动态. 水生态学杂志, 2008, 28 (5) : 47-51.

[20] 彭映辉, 简永兴, 王建波等. 湖北省五大湖泊水生植物多样性的比较研究. 水生生物学报, 2004, 28 (5): 
464-470.

[21] 金伯欣, 邓兆仁, 李新民. 江汉湖群综合研究. 武汉: 湖北科学技术出版社, 1991.

[22］李 勇, 苏文贵, 肖笃宁. 地理信息系统在典型区土地利用适宜性评价中的应用. 土壤, 1996, (1)：14-29.

[23] 申世广, 王 浩, 荚德平等. 基于 GIS 的常州市绿地适宜性评价方法研究. 南京林业大学学报: 自然科学版, $2009, \mathbf{3 3}(4)$ : 72-76.

[24] 王海鹰, 张新长, 康停军. 基于 GIS 的城市建设用地适宜性评价理论与应用. 地理与地理信息科学, 2009,25 (1) : 14-17.

[25] 孔 博, 张树清, 张 柏等. 遥感和 GIS 技术的水禽栖息地适宜性评价中的应用. 遥感学报, 2008, 12(6): 10011009.

[26] 陈 凤, 张安明, 邹小红. 基于主成分分析法的建设用地需求优先度研究. 西南大学学报, 2010, 32(8)： 158-162.

[27] 杨 丽, 李春宇, 余绍文等. 湿地生态完整性评价方法研究进展. 安全与环境工程, 2008, 15(4): 1-4. 